British \& Irish Botany 2(3): 207-214, 2020

\title{
A novel hybrid of Hypericum undulatum (Wavy-leaved St. John's-wort, Hypericaceae) and its subsequent dispersal
}

\author{
Andrew Jones ${ }^{1 *} ;$ Fred Rumsey ${ }^{2}$ \\ ${ }^{1}$ Aberystwyth, Wales, UK; ${ }^{2}$ Natural History Museum, London, UK
}

*Corresponding author: Andrew Jones: aberystwyth1234@gmail.com

This pdf constitutes the Version of Record published on $31^{\text {st }}$ August 2020

\begin{abstract}
The novel hybrid Hypericum undulatum Schousb. ex. Willd. $x$ H. perforatum $L$. is described from Cardiganshire (v.c.46) and given the name H. x cereticae R.A. Jones, F.J. Rumsey \& N. Robson. Despite reduced fertility it shows indications of ongoing introgression and signs of recent dispersal up to $5 \mathrm{~km}$ from the core site. The hybrid has arisen recently at the northern extremes of the rarer $(H$. undulatum) parental species' range, although at neither site are the parents currently sympatric and in the outlying population both are absent, supporting the belief that here it has not arisen de novo but has colonised through unknown agencies.
\end{abstract}

Key words: Hypericum perforatum; hybridisation, dispersal

\section{Introduction}

Wavy-leaved St. John's-wort, Hypericum undulatum Schousb. ex. Willd. is a Nationally Scarce plant with a globally restricted range (Stewart et al., 1994). It reaches its northern range limit in Wales, with a small and erratic population at Cors Arthog, Merionethshire, v.c.48 (Stille, 2014) and a larger concentration of sites in north Cardiganshire v.c.46, between the lower Ystwyth and Wyre valleys (Figs.1 \& 2). This population cluster occurs mainly in wet heathy pasture, known locally as "rhos" and cut-over former peat-bogs and is mostly protected in the core area at Sites of Special Scientific Interest (SSSI).

In July 2015, on a routine monitoring visit to Rhos Cross Inn SSSI (Grid Ref. SN617729), the most inland Cardiganshire site for $H$. undulatum, RAJ found several hundred plants of another very distinct Hypericum, scattered over $c .50 \times 200 \mathrm{~m}$ of marshy grassland, in dense Juncus acutiflorus Ehrh. ex Hoffm. and Molinia caerulea (L.) Moench, in wet heath and semi-shaded valley mire and even growing under young willow carr. By contrast, the population of $H$. undulatum was concentrated here in the more flushed, open rhos.

This other Hypericum, at $60-90 \mathrm{~cm}$ tall, contrasted strongly with the smaller, neater plants of $H$. undulatum (mean height $45-55 \mathrm{~cm}$ ), growing much more vigorously and sprawling over the surrounding vegetation. It also had larger, paler and more reflexed petals; red-flushed beneath, like $H$. undulatum but with black dots and streaks, resembling $H$. maculatum Crantz or $H$. x desetangsii Lamotte (which grew nearby, along the hedge boundary at Rhos Cross Inn). The sepals were 
broader than in $H$. undulatum, with both clear- and black-dotted glands and the filaments were conspicuously longer than in that species. Additionally, whilst the leaves were abundantly dotted with translucent glands, like $H$. undulatum, they were much less undulate, and the stems were variably two- to four-winged (Fig. 3). Notably, perhaps, a number of these plants were also coated with a grey powdery mildew, Erysiphe hyperici (Wallr.) S. Blumer, whereas the H. undulatum here seemed wholly free of infection.

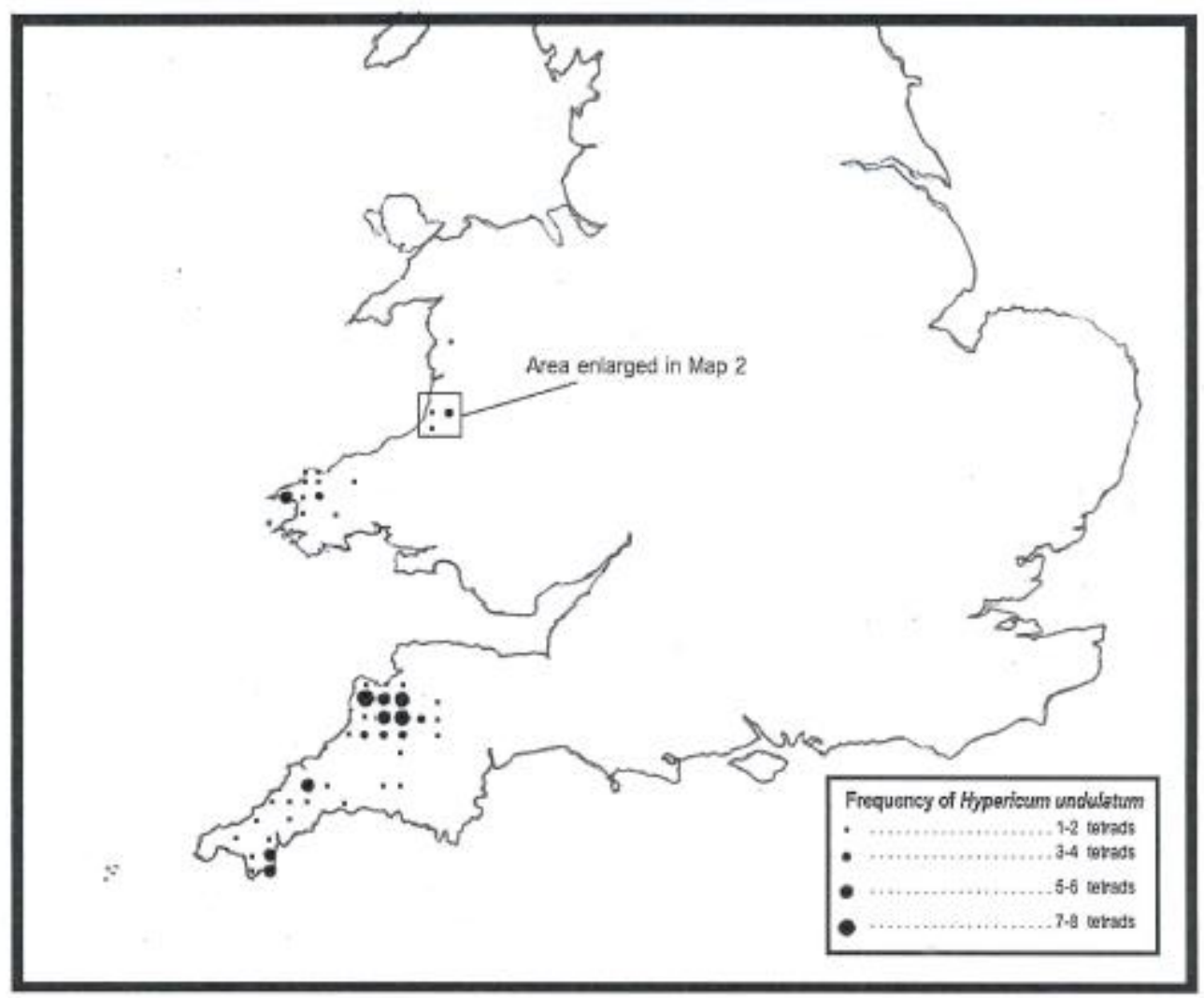

Figure 1. Distribution and frequency of Hypericum undulatum in Britain, after Stewart et. al., (1994).

Staining the pollen from this unusual Hypericum with Aceto-carmine dye revealed $c .60 \%$ apparent fertility, as opposed to $c .98 \%$ fertile pollen in the neighbouring $\mathrm{H}$. undulatum and the differences appeared even greater in terms of mature seed-output. In a sample of 10 individual plants from each taxon there were only $1-2$ apparently ripe seeds per capsule in the un-named Hypericum, whereas each of the $H$. undulatum capsules had many tens - if not hundreds - of wellformed seed. Despite this reduced fertility, the first taxon was very widespread at Rhos Cross Inn, almost certainly as a result of seed dispersal.

Collectively, these features all strongly suggest a hybrid between $H$. undulatum and a species in Section Hypericum. Dr Norman Robson, the BSBI Referee for Hypericaceae was promptly able to determine the parentage of this population as $H$. undulatum $\times$ H. perforatum $\mathrm{L}$. (Perforate St. John's-wort), a combination new to science - but unfortunately found too late for the new Hybrid Flora of the British 
Isles (Stace et al, 2015). Accordingly, we now formally describe the hybrid, giving it the name Hypericum $x$ cereticae after the latinate form of Ceredigion or Cardiganshire.

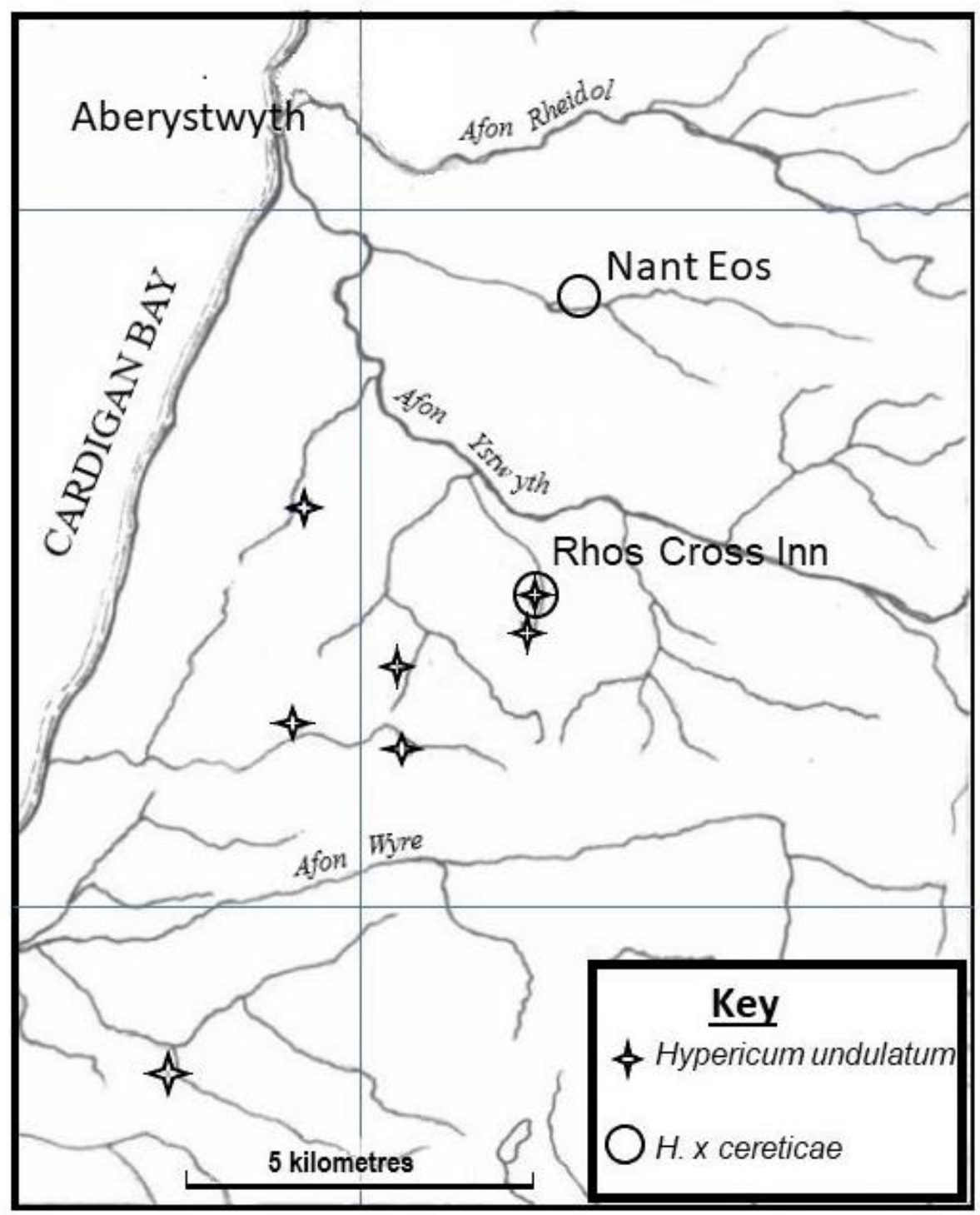

Figure 2. Local concentration of sites for Hypericum undulatum and the new hybrid in north Cardiganshire, v.c.46

We should note that the taxonomy of this Section (and in particular the rather variable, apomictic $H$. perforatum complex) has recently been revised by Sell \& Murrell (2017), recognising at least three native species in addition to $H$. perforatum s. str.: H. densifolium P.D. Sell, and two segregates previously recognised by Jordan, $H$. lineolatum Jord. and $H$. microphyllum Jord. Robson (pers. comm. 2019), however, has painstakingly monographed this genus globally over more than 50 years and remains unconvinced by Sell's approach, and these segregates have not yet generally been adopted (see e.g. Stace, 2019). We have not attempted to identify which segregate may be involved in $\mathrm{H}$. $\times$ cereticae, and further study of this complex is required. 


\section{Description}

Hypericum $\times$ cereticae R.A. Jones, F.J. Rumsey \& N. Robson Hybrid nov. Holotype: Cardiganshire, v.c.46, Rhos Cross Inn, SN617729, July 2019, R.A. Jones sn. BM; (BM013848257)

Perennial erect to sprawling herb with slender rhizomes, stems to $90 \mathrm{~cm}$, glabrous, pale green tinted reddish, variably 2 to 4 -winged, the wings narrow $<0.2 \mathrm{~mm}$ wide; branched through much of the stem, the upper branches long and bearing flowers at apex, borne at $50-70^{\circ}$ to the axis, the lower short and sterile, more erecto-patent; Leaves opposite, medium green on upper surface, a little paler beneath, with round sessile black translucent glands, leaves on main stem larger $(20-30 \times 8-11.5 \mathrm{~mm})$ but of similar shape to those on the branches, oblong-ovate, apex obtuse, entire somewhat undulate, sessile, some partly amplexicaul, some branch leaves minutely petiolate; flowers in large clusters at end of main stem with smaller clusters at ends of upper branches, up to $c .25 \mathrm{~mm}$ diameter; sepals 5, 5-6 $\times 1.2-2.1 \mathrm{~mm}$, ovate to lanceolate, apex acute sometimes shortly aristate and blackish tipped, with 0-4 linear sessile black glands; petals $7.5-13 \times 3.5-7 \mathrm{~mm}$, ovate to ovate-oblanceolate, rather asymmetric to nearly symmetric, bluntly acute, bright yellow, variously reddish coloured on the underside, with sparse blackish dotting to more extensive blackish streaks; filaments pale yellow, 7-10mm long, anthers yellow to brownish, styles 3, capsules striate, to $6 \mathrm{~mm}$, seeds few ? reticulate.

\section{Diagnosis}

Distinguished from $\mathrm{H}$. undulatum by its larger, paler, more reflexed petals, black marked beneath, broader more ovate and less acuminate sepals with fewer black glands, longer filaments, less undulate leaves and from $H$. perforatum by its petals streaked red beneath and the somewhat undulate more amplexicaul and uniform leaves. It differs from both in its vigour and sprawling habit, variably 2- or 4-winged stems and greatly reduced fertility. See illustrations in Fig. 3 and photographs in Figs. 4 and 5.

\section{Morphology and distribution}

The Rhos Cross Inn population displayed some variability in flower size and pigmentation, stem branching, stature and leaf undulation but these were perhaps mostly due to environmental factors such as shading, water stress and competition. Variation in more hereditable characters such as flower size and pigmentation could, however, reflect genetic differences and, if so, it was interesting that all this variation appeared to be in one direction, towards $H$. undulatum (i.e. a range of individuals with smaller, more red-pigmented flowers), perhaps representing a degree of back-crossing or introgression with the more fertile and only currently sympatric parent. $H$. perforatum is a pseudogamous apomict, $H$. undulatum a fertile sexual diploid. In other hybrids with $H$. perforatum as parent, eg. $H$. $\times$ desetangsii, hybridisation has been shown to be reciprocal; when acting as the female parent the apomictic taxon contributing unreduced gametes, reflected in chromosome number in the hybrid (Stace et al., 2015). It is most probable that pollen from the absent apomictic parent has been carried to the $H$. undulatum population, with the resulting 
then seed falling locally, but this would need cytological or molecular analysis.

Despite its reduced fertility, the hybrid's seed output and capacity for dispersal might indicate an inherited apomictic character from the $H$. perforatum parent (as in $H$. $\times$ desetangsii).

The population of hybrid $H . x$ cereticae was generally more widespread and abundant than $H$. undulatum at Rhos Cross Inn although, notably, it was also absent from the flushed areas where that parent species mostly occurred - and, indeed, from the nearest adjacent site for $H$. undulatum c.200m to the SW, at Rhos y Fforest. In fact, during successive, follow-up surveys the hybrid was not found at any of the other six current and former sites (including casual occurrences) for $H$. undulatum elsewhere in Cardiganshire.

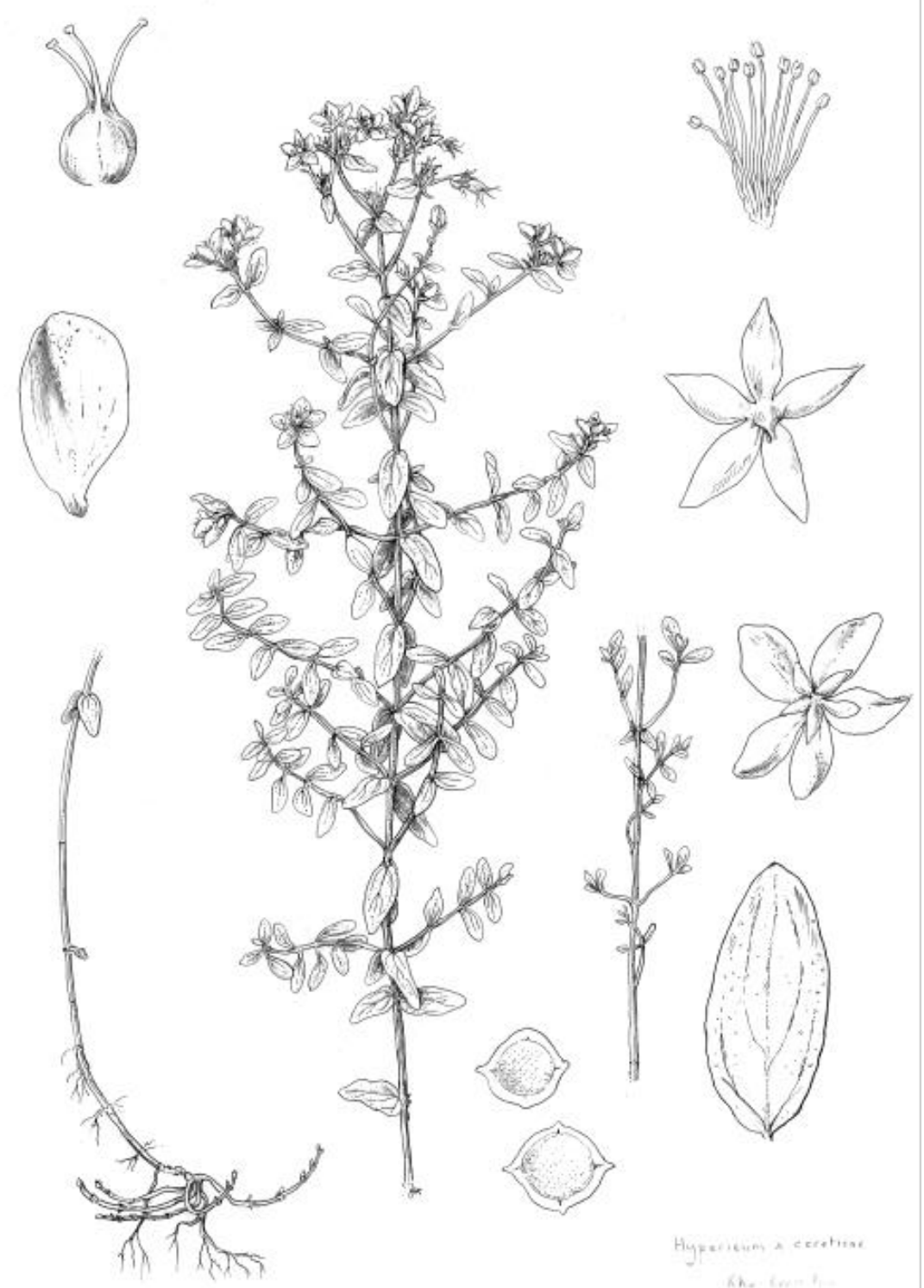

Figure 3. Hypericum $\times$ cereticae (illustration by FR) 


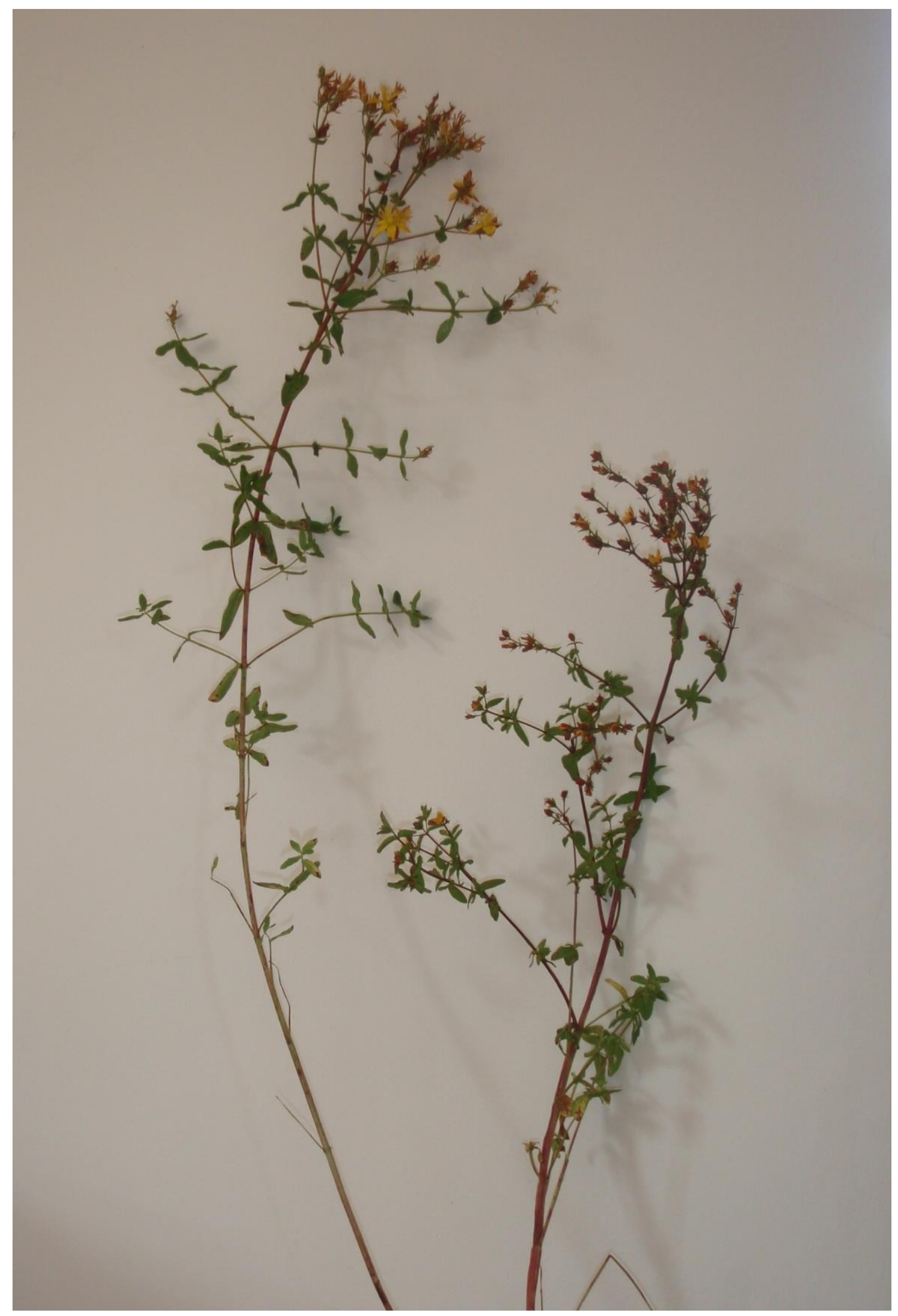

Figure 4. Hypericum $x$ cereticae (left) and $H$. undulatum (right) from the type locality (AJ) 


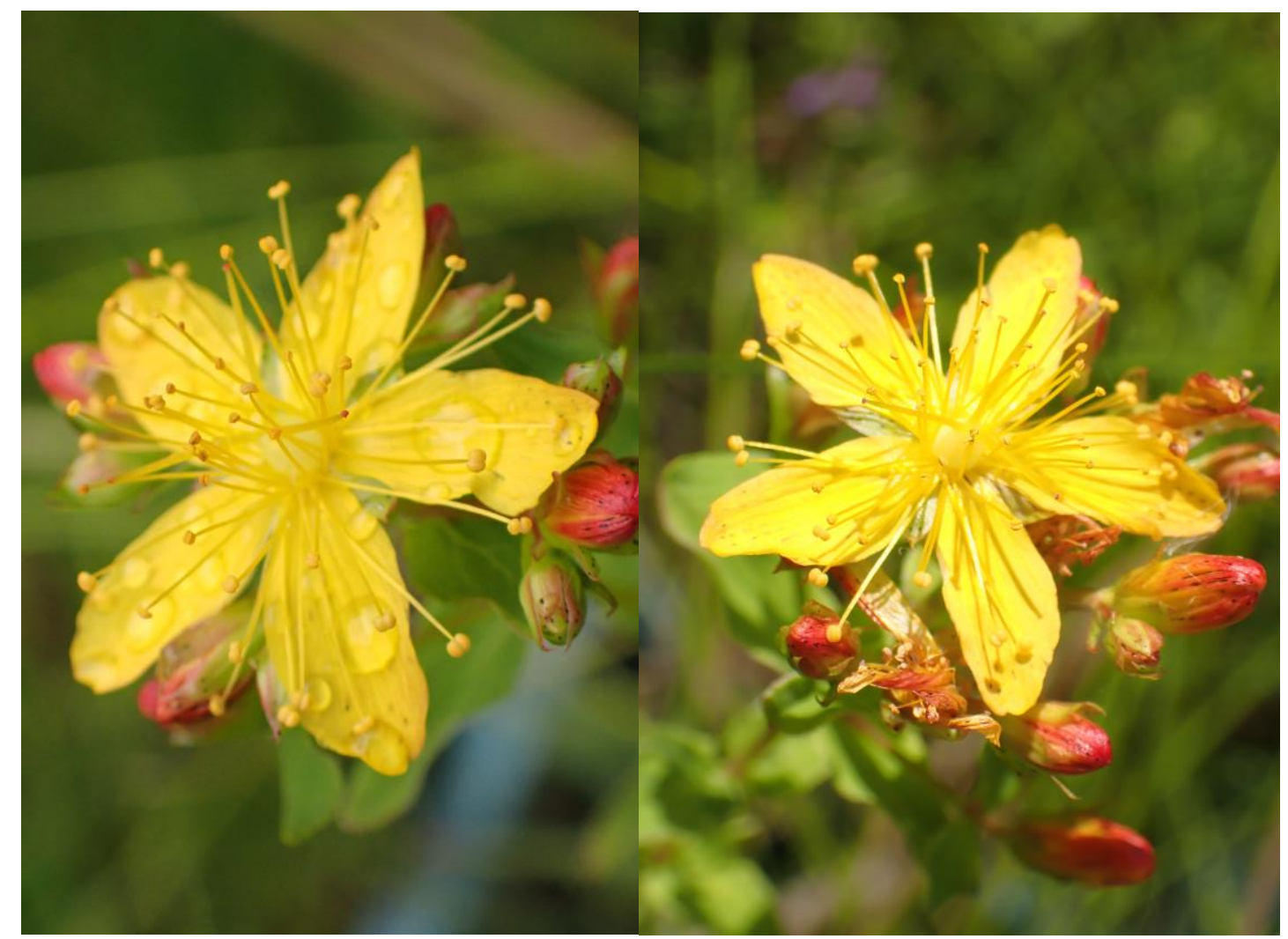

Figure 5. Flowers of Hypericum $x$ cereticae (left) and $\boldsymbol{H}$. undulatum (right) from self-sown $F 2$ progeny in cultivation (FR)

\section{Dispersal}

It is remarkable that only two months after the initial discovery, Steve Chambers, the County Recorder for v.c.46, found another population of $H$. undulatum $\mathrm{x}$ perforatum (confirmed by Norman Robson), near a small lake on the Nanteos estate (SN616.784), c.5km north of Rhos Cross Inn (Fig.2). This much smaller population of $c .25$ plants was localised over $15 \mathrm{~m}^{2}$ of dense J. acutiflorus, Angelica sy/vestris L. and Filipendula ulmaria (L.) Maxim. beside a small stream and, notably perhaps, in a much more anthropogenic setting (since the lake was originally created as a landscape feature in the early $19^{\text {th }}$ century).

Neither parent of the hybrid was found at Nanteos lake or nearby but they might both have occurred here previously, prior to historical alterations. There was, for instance, former rhos pasture $c .2 \mathrm{~km}$ downstream from Nanteos, along the Nant Paith at Rhydyfelin, and H. undulatum was recorded there by J.H Salter in 1937 and again by R. Mackechnie, as recently as 1954 .

On balance, however, an independent origin for $H$. undulatum $\times$ perforatum at Nanteos and its persistence here, unnoticed (in a well-botanised site), for $c .200$ years is less likely that than a relatively recent dispersal from Rhos Cross Inn, c.5km away. And we can probably date the spread - if not origin - of the hybrid at Rhos Cross Inn to sometime after 1995, since it was not observed then by Arthur Chater in his most recent survey (and he is unlikely to have missed such a large and relatively conspicuous population). The rapid spread and dispersal of a new hybrid are rarely observed events but consistent here with the behaviour of both parents. H. perforatum has well-known "weedy" traits and there are several casual records of 
H. undulatum in v.c.46: on roadsides at Pontrhydygroes SN738.722 in 2013; in Aberystwyth, SN592.810 in 2015, and as a garden weed near Eglwys Fach, SN676.963 (Chater, 2010). It is perhaps notable that the Nanteos population has also not been seen since 2015 , making this an apparently short-lived occurrence.

In spite of its reduced fertility a plant of $\mathrm{H}$. x cereticae from the Type locality in cultivation with FJR since 2017 has shown limited recruitment into adjacent pots up to $4 \mathrm{~m}$ from the original plant indicating that dispersal by seed is possible.

This could be a very suitable subject for molecular genetic study and it is perhaps significant that $H$. x cereticae occurs here, at the most inland, northern edge of the world range for $H$. undulatum, where this species' breeding system and reproductive barriers may be more vulnerable to breaking down.

\section{Acknowledgements}

Particular thanks to Dr Norman Robson for his prompt determination of the material (and apologies for the delays in submitting this account for publication), to Arthur Chater and Steve Chambers for historical information, mildew identification and much help in the field. Thanks also to the owners of Rhos Cross Inn and Nanteos estate and to Cinzia Sertorio (Natural Resources Wales) for arranging site access and asking some essential, basic questions.

\section{References}

Chater, A.O. 2010. Flora of Cardiganshire. Aberystwyth: Privately published.

Sell, P.D. \& Murrell, G. 2017. Flora of Great Britain and Ireland, Vol. 1. Lycopodiaceae -Salicaceae. Cambridge: Cambridge University Press.

Stace, C., Pearman, D.A \& Preston, C.D. 2015. The Hybrid Flora of the British Is/es. Bristol: Botanical Society of Britain and Ireland.

Stace, C.A. 2019. New Flora of the British Isles, $4^{\text {th }}$ ed. Middlewood Green, Suffolk: C\&M Floristics.

Stewart, A., Pearman, D.A. \& Preston, C.D. 1994. Scarce Plants in Britain. Peterborough: JNCC.

Stille, S. 2014. Merionethshire Rare Plant Register. BSBI. Available at: https://bsbi.org/wp-content/uploads/dlm uploads/MerionethshireRPR2014.pdf

Copyright retained by author(s). Published by BSBI under the terms of the Creative Commons Attribution 4.0 International Public License.

ISSN: $2632-4970$

https://doi.org/10.33928/bib.2020.02.207 